\title{
POLÍTICAS DESINTEGRADORAS DA EDUCAÇÃO PROFISSIONAL NO ESPÍRITO SANTO
}

\author{
M. LIMA* e T.G.S. PETERLE \\ Universidade Federal do Espírito Santo \\ marcelo.lima@ufes.br*
}

Artigo submetido em 12/02/2016 e aceito em 01/12/2019

DOI: $10.15628 /$ holos.2019.4114

\section{RESUMO}

O presente artigo opera com a produção material da existência na sua dimensão ontológica, ancorado em Marx e Freire, para advogar uma formação humana integral em contraposição aos processos educacionais de aprofundamento da alienação próprios da divisão técnica e social do trabalho no capitalismo. Metodologicamente, baseia-se na análise documental das informações da mídia e do Governo do Estado do Espírito Santo, tendo em vista os debates e tensões gerados na implantação do projeto "Escola Viva". No Espírito Santo, a oferta da educação profissional e do ensino médio orienta-se por um viés privatizante. A íntima relação entre setores público e privado visão hegemonizar a gestão privada além de destinar recursos escolas privadas sob o comendo do Instituto de correpsonsabilidade educacional (ICE), assim como ocorreu em Pernambuco. A atual administração, sob o pretexto de implantar escola de tempo integral, vem esvaziando a oferta de cursos técnicos integrados ao ensino médio na rede estadual. Nessa lógica, a educação deixa de ser um direito e passa a atender aos interesses mercantis, exercendo mais uma possibilidade de acúmulo pelos grupos detentores do capital. Assim, sob a justificativa de atender ao Plano Nacional de Educação 2014-2024, o Governo Paulo Hartung (gestão 2015-2018), iniciou seu mandato com duas prioridades: a implantação do projeto Escola Viva e o fortalecimento do programa Bolsa Sedu. A partir dessas análises, entendemos que o governo implanta uma política pouco dialógica e institui projetos que desintegram o direito a uma educação básica e profissional pública, integral e integradora, assumindo uma lógica empresarial de gestão e privatizante da educação.

PALAVRAS-CHAVE: educação básica, educação profissional, projeto Escola Viva, mercantilização.

\section{DISINTEGRATIVE POLICIES ON PROFESSIONAL EDUCATION IN THE STATE OF ESPÍRITO SANTO}

The present article operates with the material production of existence in its ontological dimension, anchored in Marx and Freire, to advocate an integral human formation in opposition to the educational processes of deepening alienation proper to the technical and social division of labor in capitalism. Methodologically, it is based on documentary analysis of information from the media and the State Government of Espírito Santo, in view of the debates and tensions generated in the implementation of the project "Escola Viva". In Espírito Santo, the offer of vocational education and high school is guided by a privatizing bias. The close relationship between the public and private sectors views hegemonizing private management in addition to allocating resources to private schools under the auspices of the Institute of Educational Responsibility (ICE), as occurred in Pernambuco. The current administration, under the pretext of implementing a full- time school, has been depleting the offer of technical courses integrated to high school in the state network. In this logic, education ceases to be a right and begins to cater to mercantile interests, exercising more a possibility of accumulation by the groups that hold the capital. Thus, under the justification of complying with the National Education Plan 2014-2024, the Paulo Hartung Government (2015-2018 management) began its mandate with two priorities: the implementation of the Escola Viva project and the strengthening of the Bolsa Sedu program. From these analyzes, we understand that the government implements a little dialogic policy and institutes projects that disintegrate the right to a basic and professional public education, integral and integrative, assuming a business logic of management and privatizing education.

KEYWORDS: basic education, professional education, Living School project, commodification. 


\section{INTRODUÇÃO}

A relevância da ampliação da jornada escolar vem provocando debates entre pesquisadores da área de educação. Longe de ser um consenso, a elaboração e implementação da chamada educação em tempo integral tem impactado as políticas públicas que vão nesse sentido.

O direito a uma educação integral que prepare os educandos para estudos posteriores, para a cidadania e para o mundo do trabalho já vem sendo apontado desde a Constituição Federal (CF) de 1988. Essas políticas geram implicações para a organização do currículo da Educação Básica no tempo e no espaço escolar. Paralelamente a esse fato, a relação entre a Educação Profissional técnica de nível médio e a educação propedêutica do Ensino Médio ganha mais centralidade no debate sobre a formação integral dos jovens estudantes.

Nesse contexto, sob orientação marx-freireana, este artigo aborda a formação integral dos sujeitos do Ensino Médio da rede pública estadual do Espírito Santo na perspectiva do direito a uma formação dessa natureza. Do ponto de vista teórico-metodológico e ético-político, advogamos por uma formação humana desalienadora, que se relaciona com a categoria trabalho na sua dimensão ontológica e que se contrapõe aos processos de reprodução da força de trabalho e de aprofundamento da desigualdade social. No nosso entendimento, o pressuposto da dialogicidade deve balizar os processos de implementação das políticas públicas que se colocam como direito, de modo que, na área educacional, seus principais protagonistas - gestores, docentes e, em especial, alunos - sejam os sujeitos do processo de ensino-aprendizagem.

Nessa perspectiva, passamos a analisar o quadro da ação governamental no Ensino Médio e Profissional no periodo de 2015-2018. Acreditamos que, apesar de certo esforço dos governos passados - que, de modo ainda muito tímido, começaram a estruturar a oferta de Educação Profissional numa articulação com a oferta de Ensino Médio-, desde janeiro de 2015, o sistema estadual de ensino vem sofrendo a imposição para implantar o projeto "Escola Viva", processo o qual este artigo se dedica a analisar.

Essa política, segundo a equipe do governo Paulo Hartung (2015-2018), tem como objetivo ampliar a jornada escolar diária de quatro para nove horas e trinta minutos. Segundo os gestores da área de educação no Estado do Espírito Santo, além de planejar, executar e avaliar um conjunto de ações inovadoras em conteúdo, método e gestão da Educação Básica, essa proposta está direcionada à melhoria da qualidade do Ensino Médio. Sua formulação e gestão são baseadas no Instituto de Co-responsabilidade pela Educação (ICE), organização privada sem fins lucrativos que conta com o auxílio de outros parceiros (também empresas privadas). Assim, o modelo propõe a criação e implementação de uma rede de escolas públicas estaduais de Ensino Médio em turno único, a serem geridas pelo setor privado.

Para avaliar a proposta política imposta pelo governo, vamos problematizar o projeto "Escola Viva", tomando por base a análise documental das informações divulgadas pela mídia e pelo Governo do Estado do Espírito Santo, tendo em vista os debates e tensões gerados a partir da divulgação do projeto e suas implicações para a política de Educação Básica e Profissional. 


\section{BASES LEGAIS DA INTEGRAÇÃO CURRICULAR}

Há diversos dispositivos legais que indicam, legitimam e mesmo obrigam a integração curricular dos docentes, discentes, conteúdos, espaços e tempos educativos nos diversos níveis, etapas e modalidades da educação escolar. De modo mais direto, destacam-se os que, na CF/1988 e na Lei de Diretrizes e Bases da Educação Nacional (LDB - Lei no 9.394/1996), versam sobre os objetivos da educação escolar. Para a CF/1988, a educação visa "ao pleno desenvolvimento da pessoa, seu preparo para o exercício da cidadania e sua qualificação para o trabalho" (art. 205) (BRASIL, 1988). Evidencia-se uma correlação entre a educação geral e a educação técnica, na medida em que o próprio desenvolvimento da pessoa pressupõe, na sua formação, o desenvolvimento nos âmbitos físico, cognitivo, moral, social e produtivo, referindo-se esse último às capacidades técnicas psicomotoras, relacionais e tecnológicas. Também podemos destacar que o exercício da cidadania não se faz sem a apropriação dos conhecimentos sociais e econômicos que envolvem o trabalho como relação social e como processo produtivo.

A atual LDB (art. 1오 § 2) afirma que a educação escolar deve se vincular e se desenvolver no mundo do trabalho, com vistas a fornecer ao educando "os meios de progredir no trabalho e em estudos posteriores" (BRASIL, 1996). Nesse caso, a Educação Básica assume um duplo papel, de continuidade e terminalidade, sem perder de vista a importância da contextualização e do vínculo da educação com a prática social e com a realidade em suas dimensões tecnológica, científica e produtiva.

Neste sentido, para cumprir os objetivos educacionais assumidos pela legislação ${ }^{1}$, a atual Lei de Diretrizes e Bases, de modo ainda mais detalhado, regulamentou a oferta de Educação Profissional técnica de nível médio na sua forma integrada ao Ensino Médio, com a finalidade de promover "a preparação básica para o trabalho" (art. 35, incisos II e IV), de modo que o educando seja "capaz de se adaptar com flexibilidade a novas condições de ocupação" (art. 36, § 10, incisos I e II). Porém, esse dispositivo legal destaca que se deve propiciar ao educando "a compreensão dos fundamentos científico-tecnológicos dos processos produtivos, relacionando a teoria com a prática, no ensino de cada disciplina". Nesses termos, ao final do currículo do Ensino Médio, os educandos devem demonstrar o "domínio dos princípios científicos e tecnológicos que presidem a produção moderna" (art. 36, § 1ㅇ, inciso I) e ter o "conhecimento das formas contemporâneas de linguagem" (art. 36, § 1ㅇ, inciso I). Assim, esses dois itens devem ganhar destaque, ser avaliados e revistos no âmbito do currículo do Ensino Médio (BRASIL, 1996).

Por essa lógica proposta pela atual LDB, "o Ensino Médio, atendida à formação geral do educando, poderá prepará-lo para o exercício de profissões técnicas" (BRASIL, 1996). Ou seja, conforme a norma vigente, "a preparação geral para o trabalho e, facultativamente, a habilitação profissional poderão ser desenvolvidas nos próprios estabelecimentos de Ensino Médio ou em cooperação com instituições especializadas" (seção IV-A, art. 36-A, parágrafo único). Assim, a

\footnotetext{
${ }^{1}$ Vale lembrar o objeto em tela antecede a reforma do ensino médio inciada pela Medida Provisoria 746/2016 e consolidada pela lei 13415/2017.
} 
Educação Profissional técnica de nível médio pode ser ofertada na forma de cursos técnicos integrados ao Ensino Médio (seção IV-A, art. 36-B, incisos I e II).

No que diz respeito aos Institutos Federais de Educação, Ciência e Tecnologia (IFs) ${ }^{2}$, entre as principais finalidades de sua criação estão "promover a integração e a verticalização da Educação Básica à Educação Profissional [...]" (seção II, art. 60, item III). Ou seja, cabe aos IFs "ministrar Educação Profissional técnica de nível médio, prioritariamente na forma de cursos integrados, para os concluintes do Ensino Fundamental e para o público da Educação de Jovens e Adultos" (Seção III, art. 70) (BRASIL, 2008).

As orientações nacionais constantes das normas federais acerca da integração do Ensino Médio à Educação Profissional estão reafirmadas nas normas locais. O conteúdo normativo desse conjunto jurídico demonstra reiteração e sintonia entre as determinações educacionais em seus diversos níveis.

Do ponto de vista normativo, mais recentemente, em 2012, novas regras estabeleceram, ainda com mais detalhes, parâmetros para a integração curricular. Foram baixadas pelo Conselho Nacional de Educação (CNE) novas diretrizes curriculares para orientar a construção do currículo no âmbito da Educação Profissional técnica de nível médio. Tal formulação tem consequências diversas sobre o processo em curso nas unidades e sistemas de ensino de implantação do Ensino Médio Integrado.

A Resolução CNE n 6/2012 (art. 4ㅇ) retoma os fins e objetivos da educação já explicitados na LDB/1996 e na CF/1988, afirmando que:

a Educação Profissional técnica de nível médio, no cumprimento dos objetivos da educação nacional, articula-se com o Ensino Médio e suas diferentes modalidades, incluindo a Educação de Jovens e Adultos (EJA), e com as dimensões do trabalho, da tecnologia, da ciência e da cultura (CONSELHO NACIONAL DE EDUCAÇÃO, 2012, acesso em: 10 mar. 2014).

Aqui, reitera-se a dupla intencionalidade de se propiciar, "simultaneamente, a qualificação profissional e a elevação dos níveis de escolaridade dos trabalhadores". Além da finalidade de "proporcionar ao estudante conhecimentos, saberes e competências profissionais necessários ao exercício profissional e à cidadania, com base nos fundamentos científico-tecnológicos, sóciohistóricos e culturais" (CONSELHO NACIONAL DE EDUCAÇÃO, 2012, acesso em: 10 mar. 2014).

A partir da aprovação da Lei no 10.172/2001, que instituiu o Plano Nacional de Educação (PNE) vigente no período 2001-2011, acirrou-se ainda mais o debate sobre a formação integral. 0 plano previa que as escolas deveriam dar atenção especial às crianças de baixa renda, oferecendoIhes a educação em tempo integral, com ampliação da jornada escolar para sete horas diárias (BRASIL, 2001).

Durante o período de execução do PNE 2001-2011, houve grande ganho para a educação, a partir do Fundo de Manutenção e Desenvolvimento da Educação Básica e de Valorização dos Profissionais da Educação (Fundeb). Tal fundo foi criado pela Emenda Constitucional no 53/2006, com regulamentação feita pela Lei $n=11.494 / 2007$ e pelo Decreto $n=6.253 / 2007$, e veio substituir

\footnotetext{
${ }^{2}$ A Lei no 11.892/2008 instituiu a Rede Federal de Educação Profissional, Científica e Tecnológica, criando os IFs.
} 
o Fundo de Manutenção e Desenvolvimento do Ensino Fundamental e de Valorização do Magistério, vigente no período 1998-2006. O Fundeb permitiu que os investimentos financeiros, destinados anteriormente de maneira prioritária para o Ensino Fundamental, passassem a atender também à Educação Infantil e ao Ensino Médio, bem como à Educação de Jovens e Adultos, de forma a tirar da marginalidade essas etapas e modalidades da Educação Básica.

Todo esse contexto vivenciado na educação brasileira interfere diretamente na temática da formação integral, educação de tempo integral e qualidade como direito. Portanto, a necessidade de se regulamentar o direito social à educação se efetiva com a aprovação da Emenda Constitucional no 59/2009, trazendo a obrigatoriedade do ensino dos quatro aos 17 anos de idade até 2016. Esse aspecto vai ao encontro da Meta 3 do novo PNE (BRASIL, 2014), que, para o ensino médio, propõe universalizar, também até 2016, o atendimento escolar para a população dos 15 aos 17 anos e elevar a taxa de matrícula para 85\% até o fim da vigência do plano, que é de 10 anos (2014-2024).

Por fim, de forma substancial, o novo PNE traz indicação, por meio de suas metas, do que se deve fazer para garantir o direito social à educação. No que se refere à educação integral, especificamente, a Meta 6 aponta: "oferecer educação em tempo integral em, no mínimo, 50\% (cinquenta por cento) das escolas públicas, de forma a atender, pelo menos, 25\% (vinte e cinco por cento) dos (as) alunos(as) da educação básica" (BRASIL, 2014). O plano aborda ainda algumas estratégias para que tal meta seja alcançada:

6.1) promover, com o apoio da União, a oferta de Educação Básica pública em tempo integral, por meio de atividades de acompanhamento pedagógico e multidisciplinares, inclusive culturais e esportivas, de forma que o tempo de permanência dos(as) alunos(as) na escola, ou sob sua responsabilidade, passe a ser igual ou superior a 7 (sete) horas diárias durante todo o ano letivo, com a ampliação progressiva da jornada de professores em uma única escola; 6.2) instituir, em regime de colaboração, programa de construção de escolas com padrão arquitetônico e de mobiliário adequado para atendimento em tempo integral, prioritariamente em comunidades pobres ou com crianças em situação de vulnerabilidade social; 6.9) adotar medidas para otimizar o tempo de permanência dos alunos na escola, direcionando a expansão da jornada para o efetivo trabalho escolar, combinado com atividades recreativas, esportivas e culturais (BRASIL, 2014).

Para enfrentar a especificidade do ensino integral e colocar em debate a reforma curricular no Ensino Médio, o Governo Federal iniciou algumas ações que encontram lugar no programa Brasil Profissionalizado. Tal programa visa a fortalecer as redes estaduais de Educação Profissional e Tecnológica, contando com o repasse de recursos da União, de forma que os estados ampliem os investimentos em suas escolas técnicas.

Ainda, o Brasil Profissionalizado tem o objetivo de possibilitar a modernização e expansão da oferta de Ensino Médio integrado à Educação Profissional da rede dos IFs; do Programa Nacional de Integração da Educação Profissional com a Educação Básica na Modalidade de Educação de Jovens e Adultos (que se propõe integrar a Educação Profissional à Educação Básica, almejando a superação da dualidade trabalho manual e intelectual); do Ensino Médio Inovador e do Pacto Nacional em Defesa do Ensino Médio, visando a fortalecer as propostas curriculares inovadoras nas escolas desse nível de ensino. 
Assegurar que o tempo dos estudantes na escola seja ampliado, buscando uma formação integral dos sujeitos, que minimize a condição imposta pelo capitalismo - que os reduz à condição de objeto - e os conduza a uma formação libertadora e emancipatória, como ser social produtor de sua própria história e da transformação da realidade, implica compreender que "a educação, como prática da liberdade, é um ato de conhecimento, uma aproximação crítica da realidade" (FREIRE, 1980, p. 25).

Nessa lógica, com ou sem o PNE, podemos afirmar que se gerou, à luz da experiência internacional, uma ideia de que o ensino integral é a nova panaceia para a educação brasileira. Muitos estados e municípios têm se organizado e se movimentado para implementar projetos que buscam a formação integral e também a ampliação da jornada educacional diária. Diante desse panorama, podemos dizer que o debate da educação integral está posto. Contudo, devemos nos atentar à execução das propostas e projetos que dizem atender a essa nova demanda.

\section{O DISCURSO DO GOVERNO DO ESTADO DO ESPÍRITO SANTO(2015-2018)}

Com o discurso de "dar prioridade à educação", o atual governo vem propondo e impondo um novo modelo de escola a ser implantado no segundo semestre de 2015. A afirmação de seus representantes é que, para atender ao que está proposto na Meta 6 do PNE 2014-2024 e melhorar a qualidade do ensino, as escolas estaduais deverão receber o projeto Escola Viva, cuja pretensão é a de criar uma escola "para os jovens". "Uma escola 'alto-astral', atrativa" que vai ajudar os educandos a construírem "um projeto de futuro" do qual suas "famílias" poderiam "se orgulhar" (COMEÇAM, 2015, acesso em: 14 jun. 2015).

Segundo o secretário de Educação do Estado do Espírito Santo, Haroldo Correa Rocha, essa política consiste na ampliação da jornada escolar em turno único para alunos e professores e deverá contar com um projeto pedagógico consistente e previamente determinado. Conforme mencionado, o projeto deverá ser gerido pelo ICE, organização privada que atuou em política idêntica em Pernambuco ${ }^{3}$ e que também foi a responsável pela formatação do Escola Viva. Nesse movimento, o governo estadual, além de deslegitimar a autogestão da Secretaria Estadual de Educação (Sedu) e das escolas, bem como as escolhas dos alunos e professores, transfere para o setor privado a organização de tal projeto.

Segundo o site do ICE, o projeto terá "atividades pedagógicas curriculares e outras desenvolvidas pelos parceiros institucionais com foco em temas como empregabilidade, associativismo, empreendedorismo, qualificação profissional, dentre outras", que levará aos alunos, "além de conhecimento, bom convívio" (SOBRE, acesso em: 6 jun. 2015). Conforme o ICE, no projeto, "os jovens serão protagonistas" e as escolas contarão com "salas temáticas", "muita tecnologia", "esporte, cultura, lazer", bem como "refeições adequadas" para ficarem num horário ampliado (COMEÇAM, 2015, acesso em: 14 jun. 2015). Para institucionalizar essa política, o Governo do Estado do Espírito Santo enviou o Projeto de Lei Complementar no 4/2015 em caráter de urgência

\footnotetext{
$5^{3}$ Ver dissertação de Edima Verônica De Morais, com o título "Utilizações das escolas de referência em Ensino Médio pelo Governo do Estado de Pernambuco: uma análise do Programa de Educação Integral”, defendida em 2013 junto ao Programa de Pós-graduação em Educação Contemporânea da Universidade Federal de Pernambuco.
} 
para Assembleia Legislativa do Espírito Santo (Ales), apontando, desse modo, sua intencionalidade em atender aos interesses do empresariado.

Na Escola Viva, o tempo de permanência dos estudantes será ampliado das quatro horas usuais para um período de nove horas e 30 minutos diárias no máximo e sete horas e 30 minutos, no mínimo. Com atividades pedagogicamente orientadas, a jornada de trabalho dos docentes e equipe gestora também deverá passar para 40 horas semanais, em regime de dedicação exclusiva. Tomada de surpresa, a comunidade escolar reagiu rapidamente e mobilizou-se por meio das redes sociais, agregando a partir daí um maior número de insatisfeitos com o modo como tal política estava sendo posta para execução.

Figura 1: Protesto realizado pelas ruas de Vitória contra a proposta do projeto Escola Viva.

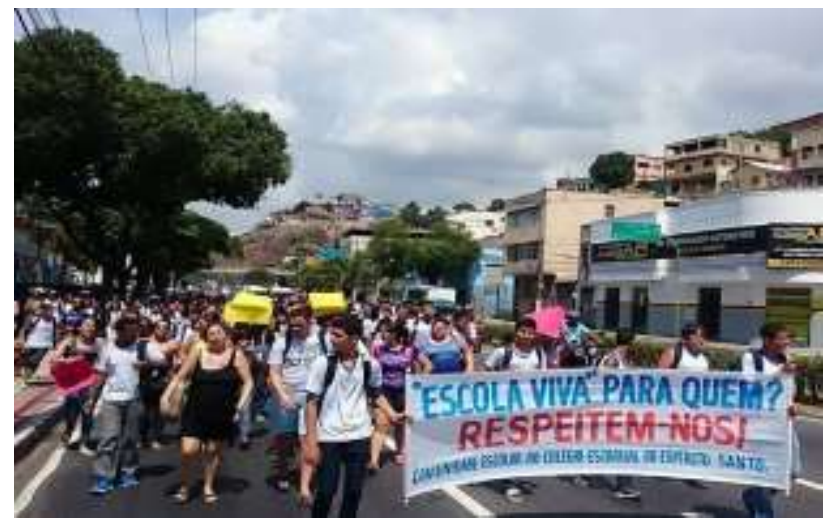

Autor: Raphael Garcia (Fotógrafo do Folha Vitória)

Fonte: Disponível em: <http://www.folhavitoria.com.br/geral/noticia/2015/03/alunos-protestam-contra-escola-vivae-complicam-o-transito-em-vitoria.html. Acesso em: 24 mar. 2015.

Conforme se vê na imagem (Figura 01), apesar das pretensões do governo, a proposta não teve aceitação de professores e de alunos, que foram às ruas protestar, demonstrando-se indignados, por compreenderem que o diálogo com a comunidade escolar não ocorreu. Um pânico sobre a possível mudança no que diz respeito à rotina escolar e à vida funcional instaurou-se sobre todos aqueles que se viram diretamente afetados e prejudicados, uma vez que as escolas que funcionavam em dois turnos passariam a atuar em turno único.

Pelo projeto, os professores atuantes na escola selecionada nela não poderão permanecer caso não consigam atuar em regime de dedicação exclusiva, mesmo que há anos já trabalhem ali como efetivos. O pior fica para aqueles que, apesar de desejarem participar, estarão impedidos, por serem concursados também em outra rede. Além disso, é claro que aqueles professores que foram contratados em regime de designação temporária serão demitidos ou remanejados. Muitos já estão com a vida organizada e quase que com certeza terão que procurar outra escola, caso o Escola Viva se efetive. Essas tensões culminaram em mobilização da categoria, que se viu obrigada a exigir maior diálogo e participação, conforme aponta a Figura 02. 
Figura 2: Folder da campanha de mobilização realizada pelo Sindicato dos Trabalhadores em Educação Pública do Espírito Santo contra a falta de diálogo na implementação do projeto Escola Vista.

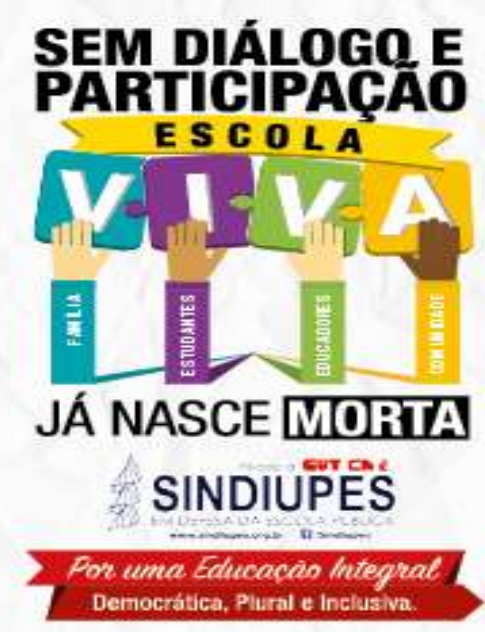

Fonte: Disponível em: http://sindiupes.org.br/blog/sem-dialogo-e-participacao-escola-viva-ja-nasce-morta/banner_escola-viva/, 05/05/2015. Acesso em: 2 jun. 2015.

Acrescenta-se ainda que os alunos que já frequentavam a escola selecionada como piloto para tal projeto e que não puderem, por motivo de trabalho, cursos, entre outros, dispor dessa nova jornada também serão obrigados a se matricular em outra escola.

"Escola Viva: modelo não atende à renovação, por isso dizemos não" foi uma das frases estampadas nos diversos cartazes das manifestações em frente à Assembleia Legislativa. Com esses e outros dizeres, os alunos protagonizaram uma importante reação ao projeto do governo, que, sem diálogo com a comunidade escolar, não conseguiu convencê-los sobre a pertinência do projeto.

O que se observa é que, na elaboração do projeto Escola Viva, não houve discussão com a comunidade. $\mathrm{O}$ que se presenciou foi a imposição do governo ao querer implementar tal modelo no Estado do Espírito Santo (uma vez que o projeto foi encaminhado à Ales para aprovação em caráter de urgência), como possibilidade de instituir sua "marca" na educação capixaba. Vale ressaltar que outros programas políticos já trouxeram para o Estado a intencionalidade de uma educação de tempo integral, como o recente Programa Ensino Médio Inovador, do Governo Federal, instituído pela Portaria no 971/2009, cuja intenção foi de "apoiar e fortalecer a criação de propostas curriculares inovadoras, ampliando o tempo do estudante na escola por meio da inserção de práticas que tornem o currículo mais dinâmico" (BRASIL, 2009).

Na gestão anterior à do atual governo, em 2012, a Sedu aderiu a esse programa, que vinha ganhando o gosto e a confiança da comunidade escolar, além de recursos próprios advindos do Governo Federal. Na atual gestão, o Governo do Estado do Espírito Santo optou por não dar 
continuidade ao programa. Nota-se, assim, claramente, um interesse privado, o que faz lembrar Chauí (2000, p. 383-384): "quando a lei coincide com a vontade pessoal e arbitrária do governante, não há política, mas despotismo e tirania", e não um novo modelo de escola, como sugerido pelo governo.

Os representantes do governo mantêm-se firmes na tentativa de aprovação imediata. Todavia, as frequentes manifestações contrárias ao projeto fizeram com que fosse retirado o caráter de urgência para sua aprovação na Ales, embora não tenha havido desistência da intenção de implementá-lo ainda no segundo semestre de 2015, insistindo que o projeto Escola Viva, além de vir ao encontro da Meta 6 do PNE 2014-2024, vai garantir a melhoria da qualidade da educação estadual.

Para alcançar tal objetivo, no entanto, há muito que se fazer, pois, como indicam os índices de fluxo escolar, bem como as avaliações em larga escala - tais como o Exame Nacional do Ensino Médio (Enem) e o Programa de Avaliação da Educação Básica do Espírito Santo -, a educação no Estado possui muitos problemas a serem enfrentados. Lima e Silva (2013), por exemplo, afirmam que, quando comparadas com outras redes de Ensino Médio e Profissional (federal e particular) ou com outras redes estaduais, as escolas do Espírito Santo estão nas últimas posições, considerando que, no Estado do Espírito Santo, somando-se as redes, contabiliza-se um total de 442 escolas no Ensino Médio e, dessas, apenas 117 obtiveram média igual ou superior à média mínima no desempenho do Enem em 2012. Para agravar, do referido total, apenas 31 escolas pertencem à rede estadual, sendo as demais ligadas às redes federal e privada.

Paralelamente a isso, o Índice de Desenvolvimento da Educação Básica do Estado do Espírito Santo está bastante aquém daquilo que os jovens capixabas estudantes das escolas públicas estaduais necessitam para ter garantido na forma de política pública seu direito à educação e ao trabalho.

Figura 3: Índice de Desenvolvimento da Educação Básica do Ensino Médio no Estado do Espírito Santo (2007-2013).

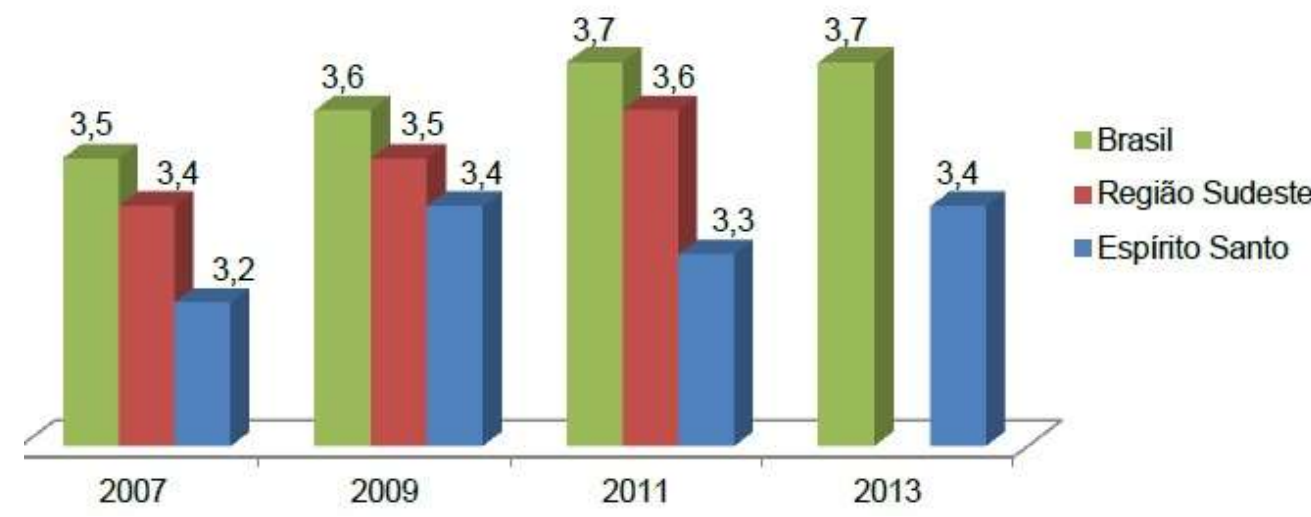

Fonte: Observatório do Plano Nacional de Educação (apud ESPÍRITO SANTO, acesso em: 10 maio 2015). 
A análise do gráfico da Figura 3 deixa clara a necessidade de uma retomada de forças para que o direito social e a qualidade social sejam realmente garantidos. Contudo, diante do exposto, perguntamo-nos: está o governo atual preocupado com a qualidade da educação pública oferecida? Em que bases dialógicas (ou autoarbitradas) dá-se a implementação da suposta formação integral? Quais as possibilidades desse projeto para transformar os educandos em sujeitos críticos, capazes de promover sua emancipação social?

Considerando que a resposta seja positiva, outros fatores nos levam a mais uma dicotomia: como um Estado que busca a qualidade da educação como um direito de todos e compreende a educação integral como essencial para a formação humana proíbe a oferta de novos cursos técnicos concomitantes, subsequentes e integrados ao Ensino Médio, além de determinar que não haja novas matrículas para os cursos já existentes nas escolas estaduais, conforme veremos a seguir?

\section{EDUCAÇÃO PROFISSIONAL INTEGRADA AO ENSINO MÉDIO VERSUS ESCOLA VIVA}

Apesar de haver uma oferta muito tímida de Ensino Médio integrado à Educação Profissional no âmbito do sistema estadual de ensino, nos últimos anos, sobretudo no governo Renato Casagrande (2011-2014), ela obteve um importante crescimento. Tais modalidades de ensino (Ensino Médio e Educação Profissional) disputam as verbas do Estado com a alternativa privatizante estabelecida pelo programa Bolsa Sedu, que prevê a compra, pelo Estado, de vagas em cursos técnicos de escolas particulares, para atender aos alunos das escolas públicas.

Embora não apresente boa infraestrutura (a contratação de pessoal ocorre sem concurso e os laboratórios são deficientes), a oferta pública estadual de Ensino Médio integrado à Educação Profissional técnica de nível médio, com certa ênfase nos eixos tecnológicos de gestão e negócios, vinha se consolidando num processo de expansão com o qual o Estado do Espírito Santo começava a assumir seu papel na formação profissional da juventude capixaba.

Tabela 1: Matrículas na Educação Profissional técnica de nível médio por tipo de curso no Espírito Santo (20072013).

\begin{tabular}{ccccc}
\hline Ano & Integrado & Concomitante & Subsequente & Total \\
\hline 2007 & 2352 & 6009 & 14345 & 22.706 \\
2008 & 2601 & 5338 & 15309 & 23.248 \\
2009 & 4527 & 6136 & 15368 & 25031 \\
2010 & 8025 & 5478 & 16810 & 30.313 \\
2011 & 11955 & 6120 & 23506 & 41.581 \\
2012 & 15278 & 6096 & 23388 & 44.762 \\
2013 & 15878 & 8546 & 23075 & 47.499 \\
\hline
\end{tabular}

Fonte: Elaborada a partir de dados do Censo da Educação Básica (apud ESPÍRITO SANTO, acesso em: 10 maio 2015). 
A análise da Tabela 1 confirma, assim, que o número de matrículas nos cursos técnicos subsequentes cresceu ao longo dos anos, mas a tendência é que continue crescendo apenas nas redes particulares, pois a Sedu, tendo por base o Decreto $n=3.755 / 2015$, determinou a extinção indireta dos cursos técnicos nas escolas estaduais, o que mostra a mercantilização do processo de formação e ainda um despotismo velado, em favorecimento dos interesses do setor privado, que, como temos visto neste artigo, tem sido privilegiado no programa educacional Escola Viva.

Tal decreto foi publicado no início da gestão do atual Governo do Estado do Espírito Santo, que, no contexto de crise do Estado brasileiro e do capital, sinalizou dois movimentos na política de educação pública estadual básica e profissional: a) a ampliação e fortalecimento do programa Bolsa Sedu e b) a criação e implementação do projeto de educação integral Escola Viva, de concepção e gestão privadas. Ambas as medidas sinalizam o desmonte da oferta estadual pública de cursos técnicos nas escolas estaduais. Para tanto, com a emissão do Decreto no 3.755/2015, o governo estabelece diretrizes e providências para contenção de gastos do poder executivo estadual para o ano de 2015.

Para o ano letivo 2015, fica suspensa a tramitação de processos de solicitação de novos cursos (Ensino Fundamental, Ensino Médio, Educação de Jovens e Adultos e Profissional) para as escolas da Rede Estadual de Ensino; A suspensão mencionada no parágrafo anterior também refere-se a renovação de cursos técnicos ofertados pelas escolas estaduais (ESPÍRITO SANTO, 2015).

A partir disso, podemos entender que o governo indica claramente a direção de sua política educacional, articulando-a com o processo de mercantilização, sendo que para o ano de 2015 o secretário estadual de Educação, Haroldo Rocha, informou que deve haver um acréscimo de quase 100\% no número bolsas. De acordo com Rocha, em 2014, foram 560 vagas, mas em 2015 a intenção é elevar esse número a mil, salientando que a tendência é que essa quantidade aumente a cada ano, para que mais jovens possam ser beneficiados.

Do ponto de vista da nossa compreensão, essa medida caracteriza uma política neoliberal que colabora para o esvaziamento do poder do Estado, posicionando a Educação Profissional como moeda de troca de ações políticas. A própria qualidade social da educação fica comprometida, uma vez que a transferência de recursos para as empresas privadas se dá de forma desenfreada, desencadeando um mercado de formação, e não a formação para o mercado, além de uma massificação e suprimento do tempo dos cursos que acabam por desqualificar aquilo que teria como finalidade a qualificação. Com essa transferência de recursos às escolas privadas, segundo Cunha (2007), o Estado fortemente colabora para a acumulação do capital educacional.

\section{CONSIDERAÇÕES FINAIS}

Diante do panorama apresentado, fica difícil compreender o que significa qualidade de educação, formação integral e educação profissional para o Governo do Estado do Espírito Santo. O objetivo deste artigo não é afirmar que a educação de tempo integral estabelecida pelo projeto Escola Viva não seja importante para a busca da melhoria na qualidade do ensino e, consequentemente, para a formação integral dos sujeitos, tendo em vista que a extensão da carga horária é meta do PNE. No entanto, implementação desse projeto a "toque de caixa", sem debates 
e diálogos com os envolvidos, não permitiu a transparência no processo, tampouco deixou claro seus reais objetivos.

Paralelamente à proposição do referido projeto, interrompeu-se a criação de novos cursos e novas matrículas, em especial para a Educação Profissional integrada ao Ensino Médio, o que, no final das contas, está legitimado pelo ajuste fiscal e contenção de gastos. Porém, em contrapartida, são fortalecidos outros gastos, focados na privatização de vagas em forma de concessão de bolsas de estudos oferecidas em instituições particulares, reforçando os princípios norteadores das políticas de Educação Profissional criticados por Lima e Silva (2013), que visam a formar jovens para o mercado via mercado da formação.

O Ensino Médio deve possibilitar aos sujeitos uma formação para o mundo do trabalho, se ele desejar inserir-se na vida produtiva, ou para prosseguir seus estudos de maneira autônoma, crítica e criativa. Desse modo, entendemos que o projeto de escola em tempo integral (Escola Viva) além de antecipar a reforma do ensino médio no Espíirito Santo se articulou com desmonte da Educação Profissional oferecida nas escolas estaduais ${ }^{4}$, sem deixar de citar que esta também é uma política que está prevista no atual PNE e que merece total atenção e investimentos. A substituição parece ter como objetivo atender aos interesses pessoais dos representantes do poder, fixando sua identidade numa ação/política que deveria ser pública e de interesses de todos, mas que se volta aos interesses do setor privado.

O Brasil ainda está muito distante de uma educação integral. O atual PNE preconiza a ampliação significativa dessa modalidade de ensino, porém, existem implicações sérias na implantação desse modelo. Inicialmente, o país teria que dobrar a quantidade de unidades escolares para atender ao mesmo número de alunos em tempo integral. Ainda há muito a se melhorar no tempo de ensino ofertado aos alunos. Anísio Teixeira afirmou que a escola deve fazer bem o que pretende fazer. Desse modo, em educação, não existe solução mágica e o ensino integral não será a solução para os problemas de qualidade educacional no País.

Nos países desenvolvidos, existe uma cultura escolar de ensino em tempo integral e de formação integral. Neles, os alunos costumam chegar às unidades de ensino às oito horas da manhã, saindo às 16 horas. Mais tempo pode, sim, significar melhor aprendizado. Sabemos que é necessário ampliar o tempo de estudos, mas é necessário, também, integrar os conteúdos, relacionar a teoria com a prática e construir um currículo interdisciplinar, capaz de dialogar com as necessidades culturais, econômicas, afetivas e tecnológicas dos educandos. É preciso ter em vista as especificidades de localização, faixa etária, classe social, perfil familiar, etnia etc.

Em síntese, após as análises realizadas ao longo deste trabalho, nosso entendimento é o de que o Governo do Estado do Espírito Santo implanta uma política muito pouco dialógica e institui projetos que desintegram o direito a uma Educação Básica e Profissional pública, integral e integradora, assumindo uma lógica empresarial de gestão e privatizante da educação.

\footnotetext{
${ }^{4}$ Vale lembrar que o convenio com a união para contrução de escolas técnicas estaduais para ofertarem sensino médio integrado no programa brasilprofissionalizado não ganhou a devida atenção, sendo as obras paralizadas.
} 


\section{REFERÊNCIAS BIBLIOGRÁFICAS}

BRASIL. Constituição (1988). Constituição [da] República Federativa do Brasil. Brasília: Senado Federal, 1998.

. Lei $n^{\circ}$ 9.394, de 20 de dezembro de 1996. Estabelece as diretrizes e bases da educação nacional. Disponível em: <http://www.planalto.gov.br/CCIVIL_03/leis/L9394.htm>. Acesso em: 7 ago. 2015.

. Lei $n^{\circ} 10.172$, de 9 de janeiro de 2001. Aprova o Plano Nacional de Educação e dá outras providências. Disponível em: <http://www.planalto.gov.br/ccivil_03/leis/leis_2001//10172.htm>. Acesso em: 28 jul. 2015.

. Lei no 11.892, de 29 de dezembro de 2008. Institui a Rede Federal de Educação Profissional, Científica e Tecnológica, cria os Institutos Federais de Educação, Ciência e Tecnologia, e dá outras providências. Disponível em: <http://www.planalto.gov.br/ccivil_03/_ato20072010/2008/lei/l11892.htm>. Acesso em: 24 jun. 2015.

. Lei 13.005, de 25 de junho de 2014. Aprova o Plano Nacional de Educação - PNE e dá outras providências. Disponível em: <http://www.planalto.gov.br/ccivil_03/_ato20112014/2014/lei/l13005.htm.>. Acesso em: 13 mar. 2015.

. Portaria no 971, de 9 de outubro de 2009. Diário Oficial [da] República Federativa do Brasil,

Brasília, 13 out. 2009. Seção 1, p. $52 . \quad$ Disponível em: <http://pactoensinomedio.mec.gov.br/images/pdf/port_971_09102009.pdf>. Acesso em: 11 mar. 2015.

CHAUÍ, M. Convite à filosofia. São Paulo: Ática, 2000.

COMEÇAM trabalhos para a implantação da Escola Viva no Estado. Folha Vitória, Vitória, jan. 2015. Disponível em: <http://www.folhavitoria.com.br/geral/noticia/2015/01/comecam-trabalhos-paraa-implantacao-da-escola-viva.html>. Acesso em: 14 jun. 2015.

CONSELHO NACIONAL DE EDUCAÇÃO (Brasil). Resolução no 6, de 20 de setembro de 2012. Define Diretrizes Curriculares Nacionais para a Educação Profissional Técnica de Nível Médio. Disponível em:<http://portal.mec.gov.br/index.php?option=com_docman\&task=doc_download\&gid=11663> . Acesso em: 10 mar. 2014.

CUNHA, L. A. O desenvolvimento meandroso da educação brasileira entre o estado e o mercado. Educ. Soc., Campinas, v. 28, n. 100, p. 809-829, out. 2007 . Disponível em: <http://www.scielo.br/pdf/es/v28n100/a0928100.pdf>. Acesso em: 5 out. 2014.

ESPÍRITO SANTO (Estado). Diagnóstico da Educação do Estado do Espírito Santo. Disponível em: <http://portal.sedu.es.gov.br:85/PDFs/DIAGNOSTICO.pdf>. Acesso em: 10 maio 2015.

. Decreto no 3.755, de 2 de janeiro de 2015. Estabelece diretrizes e providências para contenção de gastos do Poder Executivo Estadual no exercício de 2015 e dá outras providências. Disponível em: $<$ http://internet.sefaz.es.gov.br/contas/contabilidade/legislacao/arquivos/normas/DecretoEstadu al3755_R2015.pdf>. Acesso em: 5 mar. 2015.

Projeto de Lei Complementar no 4/2015. Dispõe sobre a implantação do "Programa de Escolas Estaduais de Ensino Médio em Turno Único" no Estado, denominado "Escola Viva". 
Disponível em: <http://www3.al.es.gov.br/Arquivo/Documents/PLC/PLC42015.e..docx>. Acesso em: 8 jun. 2015.

FREIRE, P. Conscientização. Paz e Terra: Rio de Janeiro, 1980.

JOSÉ, Rafael. Pacotão tem mil vagas em cursos técnicos de graça. Gazeta Online, Vitória, fev. 2015. Disponível em:

<http://gazetaonline.globo.com/_conteudo/2015/02/noticias/cursos_e_concursos/3888085pacotao-tem-mil-vagas-em-cursos-tecnicos-de-graca.html>. Acesso em: 20 maio 2015.

LIMA, M.; SILVA, I. M. Ensino Médio Integrado no Espírito Santo: perspectivas do debate acerca da qualidade a partir dos resultados do desempenho de estudantes no Enem. Trabalho apresentado no Simpósio Brasileiro de Política e Administração da Educação, 2013. Disponível em: <http://www.anpae.org.br/simposio26/1comunicacoes/MarceloLima-ComunicacaoOral-int.pdf>. Acesso em: 14 jun. 2015

SOBRE o programa. Instituto de Co-responsabilidade pela Educação. Disponível em: <http://www.icebrasil.org.br/wordpress/index.php/programas/educacao-de-qualidade/escolasem-tempo-integral/foco-de-atuacao/>. Acesso em: 6 jun. 2015. 